


\section{Discursos de los (con)vencidos: Abascal, Pezuela y De la Serna frente a la guerra en Charcas (1809-1825)}

\section{Speeches by the defeated: Abascal, Pezuela and De la Serna in front of the war in Charcas (1809-1825)}

Marisa Davio ${ }^{1}$

\section{Resumen}

Aborda las perspectivas de algunos representantes del bando realista encargados de la dirección de la guerra contra los revolucionarios en Charcas, a partir del análisis de sus discursos y las estrategias que debieron idear para convencer a la población sobre su causa política y las experiencias que tuvieron en el campo de batalla. Se parte del conflicto generado por los sucesos ocurridos en Chuquisaca y La Paz en 1809 y la posterior guerra iniciada a partir de la proclamación de la junta de Buenos Aires en 1810 hasta la finalización de la misma.

Palabras clave: Realistas, proclamas, revolución, Charcas

1 Investigadora Asistente del Consejo Nacional de Investigaciones Científicas y Técnicas (CONICET). Instituto Superior de Estudios Sociales, Tucumán, Argentina. Contacto: mari.davio@gmail.com 


\section{Abstract}

The article addresses the perspectives of some representatives of the realist side in charge of leading the war against the revolutionaries in Charcas, based on the analysis of their speeches and the strategies they had to devise to convince the population about their political cause and the experiences they had on the battlefield. The starting point is the conflict caused by the events that took place in Chuquisaca and La Paz in 1809 and the subsequent war that began after the proclamation of the junta of Buenos Aires in 1810 until the end of the war.

Key words: realists, proclamations, revolution, Charcas

Esta investigación cuestiona la manera en que algunos actores pertenecientes al bando realista percibieron la guerra en Charcas $^{2}$, si consideraron posible un triunfo en dicho territorio y cómo observaron los aconteceres de la guerra desde la capital del virreinato peruano. Es decir, cómo idearon estrategias para mantener a la población altoperuana a su favor, valiéndose de toda clase de recursos lingüísticos y armamentísticos, a pesar de la dificultad geográfica y la falta de apoyo que recibían de los centros de dirigencia situados en Lima y

286 Espańa. Asimismo, aborda cómo concibieron la causa "pa-

2 También se utiliza el término Alto Perú, de acuerdo con los documentos encontrados en el contexto seleccionado, para referirse al territorio de la actual Bolivia y su relación con la guerra contra los revolucionarios del Río de la Plata. Sin embargo, la historiografía ha advertido que la terminología más acorde proveniente de tempranos tiempos coloniales era el territorio de la Real Audiencia de Charcas (Revilla Orias, 2009, p. 38). 
triota" o revolucionaria y qué expectativas fueron asumiendo sobre el conflicto y la posibilidad de triunfo.

En este trabajo, se analizan las proclamas, exhortaciones, intercambios epistolares y memorias emitidas por representantes claves de la dirigencia y del ejército realista, como lo fueron Fernando de Abascal, virrey del Perú durante el período 1806 a 1816, Joaquín de la Pezuela, jefe del Ejército Real del Perú desde 1813 y designado virrey luego del relevo de Abascal y, por último, José de la Serna, también jefe militar del mismo ejército desde 1816 y designado virrey durante la última etapa de 1821-1825. Se ha partido de los aportes historiográficos que han analizado las discrepancias entre tales actores. Dichas percepciones se contrastan con las de otros jefes y oficiales subalternos pertenecientes al mismo proyecto político, que también ofrecen un panorama complejo y acabado sobre las perspectivas de triunfo en la región.

La hipótesis considera que la dirigencia realista convocó un fidelismo a la Corona española a través de recursos lingüísticos y estrategias de guerra similares a los utilizados por los revolucionarios. Sin embargo, las diferentes experiencias y expectativas asumidas por actores del bando realista que actuaron durante la guerra en Charcas evidenciaron un panorama más complejo que el ilustrado por las autoridades residentes en Lima, lo que provocó, en ocasiones, desacuerdos y divergencias que habrían dificultado la dirigencia y el reclutamiento, como también la falta de identificación con la causa del rey, apreciada por esos actores. ${ }^{3}$

3 Cabe acotar que esta hipótesis no considera como única causa dichas divergencias de opinión en relación con el conflicto en el suelo altoperuano, ni que las mismas fueran esencialmente ideológicas, sino que estas 
En trabajos anteriores, he sostenido que las estrategias discursivas y los conceptos políticos empleados en las cartas, notificaciones entre jefes y oficiales, arengas y proclamas dirigidas a las tropas de los bandos realistas y revolucionarios se habrían constituido en esenciales para lograr un convencimiento e identificación con la causa política que debían defender. Ante la escasez de municiones, armamentos, vestimenta y alimentos necesarios para abastecer al ejército, las palabras difundidas entre la oficialidad y las tropas se habrían convertido en la base fundamental para sostener la causa política. ${ }^{4}$

Los planteamientos historiográficos de las últimas décadas han procurado repensar el proceso desde una óptica cualitativamente diferente, que parte de la repercusión que tuvo para los coetáneos la crisis política de la monarquía hispánica en 1808, la necesidad de legitimación de las nuevas instituciones creadas en representación de la soberanía real ausente y la concepción de las guerras revolucionarias como resultado de una "generalizada guerra civil" desatada en casi todo

diferentes perspectivas habrían de constituir una problemática interna más dentro de la "guerra de opinión" instalada contra los revolucionarios.

4 El trabajo forma parte de una investigación de mayor alcance basada en el análisis comparativo de los discursos de jefes revolucionarios y realistas en la guerra por la recuperación del territorio altoperuano durante los años 1809 a1819. Se analizan las representaciones sobre la guerra, el territorio, la revolución, la patria, entre otros conceptos y vocablos claves que utilizaron para convocar a las poblaciones involucradas con la guerra, reclutar a las tropas veteranas y lograr que se identificaran con la causa política que debían defender. La repercusión que tuvieron estas exhortaciones en las tropas y en otros actores intermediarios encargados de difundir la información a favor de una causa u otra -como el caso de los curas rurales- forma parte de un proyecto que se realizará en los próximos años. 
el continente hispanoamericano (Fradkin, 2010). Diversos autores han sostenido que al no existir un ejército nacional unificado, los bandos, tanto revolucionarios como realistas, debieron ganarse la adhesión de la gente para hacer la guerra contra el enemigo (Thibaud, 2007). Además, las interpretaciones de los actores se han visto obstaculizadas frecuentemente a causa de estudios nacionales que han impedido dimensionar la visión de los protagonistas desde la óptica y el espacio por el que circulaban.

En un primer momento, los estudios sobre las perspectivas de los vencidos se han enfocado en la organización del ejército realista en América una vez producido el proceso revolucionario en Buenos Aires con sus antecedentes y consecuencias (Díaz Venteo, 1948; Luqui Lagleyze, 1996; Llontop de Sánchez Carrión, 1971) y el apoyo de las élites alto y bajo peruanas (García de Flöel 2000). ${ }^{5}$ Recientemente, han comenzado a renovarse los análisis sobre las políticas asumidas por las autoridades virreinales y jefes del ejército realista frente a la guerra (O’Phelan, 2013, 2014; Martínez Riaza, 2014), los conflictos derivados de la guerra y su visión triunfalista que provocarían el desenlace a favor de los revolucionarios (Mazzeo de Vivó, 2000, 2009; De la Puente Brunke, 2012), las similitudes entre las estrategias y recursos adoptados entre estos y los jefes del bando contrario (Sobrevilla, 2010; Ortemberg, 2012; Davio, 2015, 2016, 2017) o la reivindicación de los realistas en el contexto de la revolución, sus seguidores y

5 Según investigaciones realizadas en las últimas décadas, la historiografía tradicional, desde una concepción nacionalista, buscó los orígenes de una identidad nacional en el Perú y enfocó el análisis en los que ganaron la guerra (Hamnett, 2000; Vargas Esquerra, 2004, 2010; Orrego Penagos, 2009; Peralta Ruiz, 2006). 
la naturaleza "fidelista" de sus tropas dentro del Ejército Real del Perú (Méndez, 1991, 2005; Etcheverri, 2009, 2013).

En el espacio sur-andino, recientes trabajos han contribuido a profundizar el estudio de la guerra de la independencia en Charcas, tomando como base la comprensión de la posición asumida frente a la fidelidad a la Corona planteada por el virreinato de Lima desde los sucesos de $1809^{6}$ y el movimiento revolucionario surgido en Buenos Aires en 1810. Asimismo, se han considerado las pretensiones de autonomía asumidas por los habitantes de Charcas ante las pugnas políticas representadas por los intereses revolucionarios dirigidos desde Buenos Aires y la posición fidelista del virreinato peruano (Roca, 2007; Sala I Vila, 2011, 2016; Irurozqui, 2011, 2014, 2016; Revilla Orias, 2009), como también las actitudes y las opciones políticas de los diferentes grupos socio-étnicos participantes en la guerra (Aillón Soria, 2010; Siles Salinas, 2009; Soux 2013, 2015).

Dentro de todo el territorio que comprendió el antiguo virreinato del Perú, ha comenzado hace algunos años un renovado interés por el estudio de múltiples procesos, perspectivas, actores e imaginarios que habían sido marginados o estudiados como procesos secundarios dentro de la historia político-institucional y de las grandes estructuras socioeco290 nómicas (Mc Evoy y Stuven, 2007; Contreras y O'Phelan, 2013; Contreras y Glave, 2015; Contreras, 2015; Ortemberg, 2014).?

6 Sobre la naturaleza y objetivos de los movimientos juntistas surgidos en La Plata y La Paz en 1809, véase Irurozqui, 2011.

7 Para el caso del Perú, véanse también otros autores mencionados anteriormente. 
Igualmente, historiadores de España y América Latina han resaltado las similitudes entre ambos procesos surgidos dentro del Imperio español y han destacado la utilización de las mismas tácticas de guerra para enfrentar al enemigo (Martínez Riaza, 2014; Démelas, 2007; Fradkin, 2010; Fraser, 2006).

La intención de este trabajo es profundizar el estudio de los actores de la trama y desarrollo de la guerra, en el marco de la lucha de ambos bandos en pugna. ${ }^{8}$ Es decir, se ha tratado de traspasar las barreras nacionales historiográficas para comprender la guerra por la recuperación del territorio altoperuano desde la perspectiva de los principales líderes y oficiales a cargo del ejército realista. Se intenta visualizar el proceso de identificación a esta causa política, los obstáculos que debieron afrontar para llevar a cabo sus fines y sus propias experiencias en el campo de batalla. Este planteamiento coincide con el debate de la historiografía iberoamericana de los últimos ańos, que trata de ampliar el panorama en el que se desenvolvían los actores con el propósito de conocer las perspectivas del conflicto, los intereses en juego y los espacios por los que circulaban y llegaban las noticias políticas de ambos bandos enfrentados.

En cuanto a los postulados teóricos del análisis planteado, se ha considerado que los aportes de la nueva historia conceptual resultan operativos para estudiar los usos y significados de los conceptos políticos y sociales del contexto histórico y espacial donde surgieron y fueron aplicados (Fernández Sebastián, 2007, 2009, 2014; Fernández Sebastián y Fuentes, 2003; Goldman, 2008).

8 Otros autores han realizado importantes aportes en este tema (Sobrevilla, 2010, 2011; Ortemberg, 2011a). 
Además, los aportes conceptuales sobre el espacio de experiencia y el horizonte de expectativas de Reinhart Koselleck permiten aprehender las experiencias de los hombres en el momento en que son vividas, de acuerdo con un pasado vivido y una visión de futuro proyectado (Koselleck, 1993, 2001).

El corpus documental está conformado por proclamas, manifiestos, autos, cartas y bandos militares hallados en colecciones documentales del Archivo General de la Nación de la Argentina, Archivo Nacional de Bolivia, Archivo General de la Nación de Lima, Perú, documentos inéditos de la Biblioteca Nacional del Perú, del Museo Histórico Militar del Perú y del Archivo de Historia y Antropología de Pueblo Libre, Lima. Esta amplia gama de documentos ha ofrecido un panorama complejo y profundo de la guerra en este espacio seleccionado y ha permitido reconocer las experiencias y perspectivas de los actores pertenecientes a ambos bandos, que se movían por espacios mucho más amplios que los delimitados por las fronteras nacionales de los países constituidos en la etapa posindependentista. Además, esta información se ha complementado con memorias ${ }^{9}$, cartas intercambiadas entre diferentes personalidades, diarios de guerra, notificaciones y partes de batalla. La metodología se ha basado en el entrecruzamiento de fuentes y el análisis de las representaciones 292 sobre la guerra.

9 Las memorias, como construcciones discursivas elaboradas posteriormente a los sucesos relatados, constituyen una forma de legitimar, reivindicar o dar cuenta de las acciones cumplidas durante los ańos de gobierno, consideraciones que deben tomarse en cuenta al analizar el corpus documental. 
El virrey Fernando de Abascal y Sousa, primer dirigente de la contrarrevolución: la cuestión de Charcas desde la capital virreinal del Perú (1806-1816).

La historiografía tradicional ha destacado en Abascal su obstinación por la defensa de una causa política que ya estaba en decadencia en América y casi no contaba con el auxilio de la metrópoli española, sumergida en la crisis de legitimidad política originada por la invasión napoleónica en 1808 y la formación de juntas que reasumieron su soberanía hasta el retorno del rey heredero de la Corona, Fernando VII.

En los últimos años, la historiografía ha tendido a desprenderse tanto de la perspectiva de los estudios románticos decimonónicos que veía en Abascal a un verdadero estratega y negociador entre los intereses espańoles y las élites americanas, como de la visión crítica del siglo XX, que lo miraba como el líder de la contrarrevolución americana, el responsable de la ruina económica del Perú y desmembramiento de la monarquía española en América (Hamnnet, 2000; Semprún y Bullón de Mendoza 2002; Vargas Esquerra 2010; Orrego Penagos, 2009; Peralta Ruiz, 2006). Es decir, se ha intentado recuperar la figura de Abascal como un personaje clave de los períodos de transformaciones políticas, sociales y económicas desde fines del siglo XVIII en América del Sur, a partir de las reformas borbónicas, hasta el período posindependentista. A pesar de la etapa conflictiva en la que debió asumir el mando, supo idear estrategias de conciliación de intereses con las élites limeñas para asegurar su fidelismo en la región. ${ }^{10}$

10 Una reciente compilación hace hincapié en los nuevos enfoques sobre la figura de Abascal y sus principales seguidores políticos, las estrategias de convocatoria, la identificación con la causa y los recursos sociales, econó- 
Fernando de Abascal y Sousa fue designado virrey del Perú en $1806^{11} \mathrm{y}$ su gobierno llegó a prolongarse diez años. Estuvo al mando de la dirigencia contrarrevolucionaria durante los años más críticos, en los que se inició el proceso independentista en América del Sur.

A través del estudio de proclamas, bandos y manifiestos emitidos por el virrey y de sus relatos transmitidos en las memorias de su gobierno, he intentado reconstruir su percepción sobre los hechos sucedidos desde las invasiones inglesas a Buenos Aires en 1806 y 1807, los movimientos de Chuquisaca y la Paz y el estallido de la revolución en la capital rioplatense. También me he preguntado acerca de su persistencia por el sostenimiento de un orden político en decadencia en América y en la propia metrópoli, de acuerdo con el contexto histórico en el cual debió desempeñar sus funciones políticas.

En sus memorias se advierte la importancia a las potentes "armas de la sugestión y el engaño"12 utilizadas por los insurgentes de Buenos Aires para hacer la guerra y difundir sus

micos y propagandísticos puestos en juego para lograr la conservación del orden colonial en esa parte del continente (O’Phelan y Lomné, 2013).

11 Gracias a su renombrada carrera militar en España, logró su ascenso y actuación en numerosos cargos en América hasta ser designado virrey del Río de la Plata en 1804, pero debido a conflictos entre las potencias no pudo asumir el cargo y fue reasignado como virrey del Perú en 1806.

12 El Diccionario de la Real Academia Española de 1739 definía la seducción como "el arte de engañar con maña y persuadir suavemente al mal". Debido a la proximidad temporal del significado otorgado por este diccionario con la época en estudio, se entiende que la seducción empleada por los jefes militares, tanto realistas como revolucionarios, fue vista con esa connotación negativa y utilizada para inculpar a los jefes disidentes por promover acciones en contra de los gobiernos de turno y adherir gente a sus filas con promesas y dádivas (Davio, 2010). 
ideales, a través de proclamas, bandos y oficios difundidos por sus principales jefes. Esto provocaba que los "alucinados incautos" se dejasen seducir por sus argumentos y se propagase la formación de juntas en el territorio altoperuano (Abascal y Sousa, 1944, p. 317). Esta herramienta también fue utilizada por sus subordinados, alentados por Abascal para difundir su causa, la lealtad al soberano legítimo y el patriotismo ligado a España.

Abascal difundió una serie de oficios y bandos en el territorio altoperuano ${ }^{13}$ en plena guerra contra los porteños. Como es sabido, muchas provincias se adhirieron a los principios revolucionarios, formaron juntas desde 1810 y prestaron apoyo al Ejército Auxiliar del Perú, que desde fines de 1810 estuvo liderado por Antonio González Balcarce y el principal representante de la junta porteña, Juan José Castelli. Desde marzo de 1812 hasta fines de 1813, asumió el cargo el general Manuel Belgrano. ${ }^{14}$ Estos jefes adoptaron una política similar a las utilizadas por los realistas, en cuanto a la exhortación y convencimiento a la causa revolucionaria, por parte de las poblaciones implicadas en la guerra por la recuperación del Alto Perú. Sin embargo, las estrategias de persuasión utilizadas por dichos actores revolucionarios, serían diferentes en relación con las resignificaciones de los conceptos claves,

13 Estos apuntan al auxilio de tropas, a diferentes jefes realistas en el Alto Perú, los pagos de sueldos, concesión de licencias y las contribuciones ordinarias para la guerra. Dichos bandos y oficios fueron hallados en el Archivo Nacional de Bolivia (ABNB), Sucre, Bolivia. Fondo Emancipación 80, 124. Colección Rück, 229.

14 Manuel Belgrano asumió nuevamente el mando en 1816, una vez derrotadas definitivamente las fuerzas revolucionarias en Sipe-Sipe al mando de Rondeau, cuya jefatura se extendió hasta la desintegración de este ejército en 1819. 
como la causa de la "patria" a la que debían defender, la "religión” o el carácter y objetivo de la revolución (Davio, 2015).

En relación con los significados que adoptó el concepto de "revolución" en este contexto de transformaciones, Fabio Waserman ha señalado que tuvo una doble connotación. Es decir, el término adquirió un significado positivo relativo a la "feliz revolución", pues los adheridos a la causa revolucionaria de Buenos Aires traerían un futuro de gloria, libertad y felicidad para todos los pueblos. En cambio, para los realistas, la revolución tenía una connotación negativa asociada a movimientos subversivos (Wasserman, 2008, pp. 161-162).

Con respecto al término "patria", en el virreinato del Perú seguía utilizándose como lugar de origen y nacimiento, si bien fue adquiriendo cierta abstracción que aludía a su paulatina asociación con la causa revolucionaria. A partir de 18121814, con los cambios introducidos por las Cortes de Cádiz, se produjo una resemantización del término, a la vez que fue asociándose con la lucha contra el despotismo en América y la consecución de la independencia (Velázquez Silva, 2014, pp. 166-173).

Un informe de Abascal de mayo de 1811 (Colección Documental de la Independencia del Perú, XXII, t. I, pp. 219-220) daba cuenta de los progresos de la causa dirigida por los revolucionarios de Buenos Aires, "cuyo interino gobierno, insiste cada día más acalorado y orgulloso en su sistema de conducir toda esta América del Sur, a sus ideas de independencia, ${ }^{15}$ a

15 Noemí Goldman señala que el vocablo “independencia” poseía diversos sentidos en la época; antes de la revolución de mayo, se le encuentra asociado a la idea de autonomía o autogestión dentro del gobierno de la 
cuyo efecto se dirigen sus conatos, los caudillos de los insurgentes" que habían "seducido" y "alucinado" con sus papeles incendiarios a la "incauta tropa y población altoperuana, cada vez más adherida a sus propuestas políticas. Sin embargo, también señalaba los progresos del ejército organizado por Goyeneche, que tenía 7000 hombres en el campamento situado en la frontera entre ambos virreinatos, dispuesto a enfrentarse con el ejército enemigo poco instruido e irregular, que contaba con 8000 a 10,000 hombres, entre los llegados del virreinato rioplatense y los reclutados en el Alto Perú.

En 1812, Abascal prometía el indulto a todos los insurgentes si "volvían al orden y la quietud alterada" y reconocían un acendrado amor al rey y a la "patria", a la vez que les hacía saber los derechos y concesiones para todos los ciudadanos, que habían sido reconocidas por las cortes españolas, como la igualdad con la clase superior del Estado, la extinción del tributo y el repartimiento de tierras a los indígenas. $\mathrm{Al}$ otorgar esta clase de concesiones, no sería necesario ya, según su juicio, seguir a los revolucionarios, que con sus similares pero falsas promesas habían llevado a todas las poblaciones a la miseria y a la devastación y provocado un inútil derramamiento de sangre (Abascal 13 de abril de 1812, Colección Documental de la Independencia del Perú, III, pp. 5-6).

Si bien la historiografía ha identificado la posición política de Abascal más acorde con un despotismo ilustrado, este debió poner en práctica algunas reformas a partir de la jura a la

monarquía, ante la crisis de legitimidad monárquica originada en España desde 1808 y la formación de juntas en Espańa y América. Una vez iniciado el proceso revolucionario, el término comenzó a vincularse a la idea de la ruptura absoluta con el gobierno español (2009, pp. 62-64). 
Constitución de 1812 para continuar en el poder virreinal ${ }^{16}$ y, probablemente, la utilización de la retórica gaditana le habría servido como recurso para intentar un acercamiento a los "obstinados insurgentes" y garantizarles el libre ejercicio de sus legítimos derechos. No obstante, las decisiones emanadas del Congreso de Viena iban a poner fin al acercamiento a las políticas liberales y una vuelta al absolutismo con el regreso de Fernando VII al poder en 1814 hasta 1820, cuando una revolución en la metrópoli española lo obligó a jurar la Constitución gaditana.

En esta inacabable "guerra de opinión", concebida así por ambos bandos, comenzaron a idearse otros recursos lingüísticos para convencer a su propia causa política, como la difusión de rumores y noticias falsas en diversos espacios de sociabilidad accesibles a toda clase de sectores sociales, calles, plazas, pulperías, atrios de iglesias, reuniones en viviendas particulares, entre otros. Esta circulación de ideas y noticias, no solo comenzó a notarse en diferentes sectores sociales, sino que, en ocasiones, estuvieron dirigidas a las mismas autoridades residentes en Espańa, probablemente para exponer un panorama más alentador y obtener el apoyo económico

16 La historiografía ha planteado este recurso utilizado por Abascal para convencer a los insurgentes de retornar a la obediencia al rey y a sus principales representantes en América, si bien en la práctica, se dedicó a restringir las soberanías y autonomías de las instituciones vigentes (Peralta Ruiz, 2001, pp. 29-56). De acuerdo con el análisis de fuentes para este trabajo, los mismos actores contemporáneos adheridos a la causa revolucionaria -como el caso de José de San Martín- descubrieron esta estrategia de acercamiento y conciliación utilizada por Abascal y otros virreyes que le sucedieron para lograr adhesión a la causa realista mediante la puesta en práctica de los derechos y principios establecidos en la Constitución gaditana de 1812. 
y armamentístico esperado de la metrópoli. Con respecto a esta última consideración, un informe de Abascal da noticias a la Corona sobre los triunfos alcanzados en Tucumán, por parte del coronel Pío Tristán, que respondiendo a las órdenes del general Goyeneche había enfrentado y abatido al enemigo al mando del general Belgrano, quien tampoco se había atrevido a enfrentarse en Tucumán y continuó su fuga. Así, las "guerrilas del rey", los habían perseguido y enfrentado "consolando a la pobre gente de haberlos libertado de tan cruel cautiverio". Asimismo, comunicaba que al conquistarse el Tucumán y lograr el control de las cuatro provincias altoperuanas, los insurgentes quedaban en un círculo bastante estrecho y próximos a ser derrotados (Abascal 13 de octubre de 1812, Colección Documental de la Independencia del Perú, XXII, t. I, p. 271).

Otras voces pertenecientes al mismo bando político de este virrey ofrecen otro panorama más cercano al conflicto con los revolucionarios. Uno de los principales jefes a cargo del ejército realista, que actuó bajo las órdenes de Abascal desde 1809 hasta 1813, fue el general José Manuel de Goyeneche. Con el transcurso de la guerra y las primeras graves derrotas sufridas en Tucumán y Salta, este general sostenía que América se hallaba cada vez más asediada por los revolucionarios y que mediante las armas y las palabras difundidas, convencían y adherían más gente a cada paso que daban, por lo que resultaba imposible la persuasión e identificación con la causa realista (Goyeneche, 20 de octubre de 1812, citado en Herreros de Tejada, 1923, p. 466).

En 1813, Goyeneche informaba los "infructuosos sacrificios a favor de la causa nacional", la falta interés de las tropas, su inútil empeño en convencerlos a continuar enlistados por 
tres años y a hablar "contra su opinión, su genio e intereses".

No obstante, esta cruda apreciación sobre la causa sería contrastada luego con la del propio Abascal, quien en sus memorias aseguraba que Goyeneche no había dirigido correctamente el Ejército Real del Perú y que junto con otros oficiales subalternos, como Pío Tristán, se habían tomado atribuciones que no les correspondían en la toma de decisiones de la guerra, que habían provocado finalmente las derrotas sufridas en Tucumán y Salta y la retirada del ejército de las provincias de Potosí, Charcas, Cochabamba y La Paz (Abascal y Sousa 1944, pp. 400, 419-420).

A ello, Abascal sumaba "los padecimientos" que debió sufrir con este general y las condescendencias y elogios que debió hacer para tenerlo contento, como también animarlo para que no abandonara su empresa militar, a causa de su necedad y deseo de un triunfo solitario (Abascal y Sousa, 1944, p. 423). Estos constantes desacuerdos entre autoridades del mismo bando habrían de influir en la falta de efectividad para la causa y en la escasa convocatoria que tenían en el suelo altoperuano.

Ante la renuncia de Goyeneche en 1813, la relación entre Abascal y Pezuela durante el período de asunción de este último como general en jefe del Ejército del Alto Perú pareció tornarse más cordial y coincidente con sus pretensiones políticas, tal como lo señala en sus memorias. ${ }^{17}$

17 El buen desempeño de Pezuela, elogiado por Abascal en sus memorias, habría contribuido probablemente a su nombramiento como virrey en 1816. 
Por su parte, el documento de renuncia de Goyeneche dirigida a V.M. en España, contrasta esta descripción del virrey, al relatar que él mismo había tenido que responder a las órdenes de un virrey que no enviaba ni recursos ni apoyo para hacer frente a la guerra y que sus disposiciones acerca de la evacuación de Potosí y demás provincias vecinas se habían debido a una decisión conjunta efectuada en una junta de guerra y no "al juicio del parcial virrey que discurre desde las comodidades de su solio" (Davio, 2016, p. 163).

Además, su experiencia en el campo de batalla le permitía señalar que la pérdida de territorios en suelo altoperuano se debía a los grandes despoblados que no permitían apoyarse en las poblaciones, los caminos largos, escabrosos y desamparados de víveres y otros recursos, como también a la crueldad de los mismos pueblos de tránsito que se convertían en ocasiones en los "más crueles enemigos" y destrozaban las tropas de ambos bandos -como lo habían hecho con Castelli en Oruro- a pesar del aplauso con que los habían recibido en un primer momento (Renuncia de Goyeneche dirigida a V.M. de España. Lima, 30 de marzo de 1814, citado en Herreros de Tejada, 1923, pp. 483-490). Esta última observación estaría haciendo alusión a la gran masa indígena que tenía sus propios intereses puestos en juego, basados en los pactos entablados con uno u otro bando y que venía implementándose desde los siglos anteriores (Soux, 2009)

Otros jefes y oficiales realistas que actuaron durante el período de gobierno de Abascal ilustraron también el panorama complejo que debieron afrontar en el territorio en cuestión, a la hora de enfrentarse al enemigo. La información sobre los sucesos ocurridos en Buenos Aires a partir de la revolución y la guerra entablada en España con los franceses era proveída 
por numerosos informantes que, atentos a los cambios políticos y movimientos del ejército revolucionario en diferentes provincias rioplatenses, prevenían al virrey las medidas más convenientes que debía tomar, al mismo tiempo que colaboraban en la conformación de su propia percepción sobre los hechos, difundidos luego en las proclamas, manifiestos y cartas. ${ }^{18}$ Uno de estos informantes fue Lázaro de Ribera, gobernador intendente del Paraguay hasta 1806 y luego nombrado gobernador de Huancavelica desde ese año. Conocedor del territorio rioplatense, envió numerosas cartas entre junio y septiembre de 1810 al virrey Abascal para ponerlo al tanto de lo ocurrido en Buenos Aires sobre la comprometida situación de Liniers en Córdoba y en el Alto Perú, ante la difusión de las ideas revolucionarias, y la grave situación y las posibilidades de ganar la batalla a través de las armas y de la "opinión pública unánime" a favor de la causa realista.

Otras cartas, intercambiadas por jefes y oficiales realistas que operaban en el espacio altoperuano, reafirman la crítica situación que enfrentaban estos actores, debido a la falta de recursos enviados desde el Perú y de la misma España, a la ausencia de motivación por parte de los integrantes de la tropas, como de los insurgentes e indígenas que acrecentaban cada vez más su número a favor de los patriotas. Así, las comunicaciones entre algunos jefes y oficiales instalados en

302 diversos puntos del territorio altoperuano dejaron evidencia de esta situación y de las percepciones negativas que ya admitían respecto de su causa y de los avances inusitados del bando contrario. ${ }^{19}$

18 Esta documentación también fue analizada en Davio, 2016.

19 Cartas intercambiadas entre Pedro Benavente, Manuel Quimper y otros funcionarios realistas que actuaron en el Alto Perú e informe levantado 
Las cartas hablan del "espanto" (Agustín de Antesana, Amiraya, 15 de octubre de 1811, en Colección Documental Emilio Gutiérrez de Quintanilla, 1973, p. 191) que estos individuos tenían ante el avance de los indios rebeldes, impulsados por sus propios intereses y no solo motivados por la causa revolucionaria. Por esta situación, los jefes realistas aconsejaban continuar seduciendo a los indígenas para que actuaran a su favor y evitar su adhesión masiva a los revolucionarios. ${ }^{20}$

Por otra parte, los bandos, oficios y proclamas difundidos por jefes que controlaban diferentes provincias altoperuanas durante los períodos de ocupación realista daban cuenta de lo acontecido durante la guerra con los insurgentes y los castigos aplicados a los adheridos a la causa enemiga. Los delitos de "infidencia" de aquellos que habían participado en alguna conspiración o intento de sublevación o de los acusados de difundir la causa revolucionaria eran sentenciados duramente. ${ }^{21}$ Tal fue el caso de muchos curas rurales que fueron sometidos a este tipo de juicios, como también de vecinos de

por el coronel Pedro Benavente basado en las noticias dadas por algunos indios. Desaguadero, 3 de septiembre de 1811. (Colección Documental Emilio Gutiérrez, t. II, pp. 99-290, 135-136).

20 Oficio de José M. de Goyeneche a Manuel Quimper en el que informa que en el Desaguadero las tropas son suficientes para sostener cualquier ataque de los indios. Cuartel General de La Plata, 10-X-1811 y oficio de Antonio de Goyburu a Manuel Quimper comunicándole que ha recibido la proclama por la que se invita a los nativos sublevados que todavía no se han rendido, a que lo hagan. Desaguadero, 28-X-1811. (Colección Documental Emilio Gutiérrez, t. II, pp. 194-195, 213). Estas cartas fueron analizadas en (Davio, 2016).

21 En sus declaraciones, estos actores debían responder sobre el grado de participación o adhesión a la causa contraria y delatar a algunos cómplices. 
la región, soldados e indígenas que defendían su apoyo a la causa realista con el propósito de ser exonerados de los cargos $^{22}$ A través de ellos, es posible detectar de qué manera la información difundida en estas proclamas, bandos y oficios llegaba a todos los sectores sociales y generaba adhesión a una causa u otra de acuerdo con sus propios intereses.

A principios de 1812, el ejército realista logró sofocar las insurrecciones indígenas y ocupar la mayoría de las provincias de Charcas (Soux, 2013) que debieron jurar la Constitución gaditana de 1812. No obstante, ante los inminentes avances de los insurgentes en dicho territorio, las proclamas de los jefes y autoridades realistas no solo eran destinadas al convencimiento de la causa, sino a las sanciones y silenciamiento de las opiniones "de los enemigos". Así, en una proclama del $2^{\circ}$ jefe del ejército realista Juan Ramírez de Orozco, emitida a fines de 1811, se establecía una serie de disposiciones a quienes se encontraran en algún tipo de relación o contacto con los revolucionarios:

(...) Que todos los individuos de la clase o sexo, que fueren y tuvieren comunicación con los rebeldes o sus caudillos, o se pasaren a su partido serán militarmente comprendidos en los que auxiliaren con víveres, dinero, armas (...) Todos los vecinos honrados, fieles defensores de la Religión, el Rey y la causa pública se alistarán en las dos compañías de vecinos (...) Todas las casas sin excepción de conventos ni monasterios, se cerrarán en sus puertas de calles, balcones y ventanas (...) Que no se permita, que el enemigo halle la cercanía del Pueblo (...) Que el que levante la voz con expresiones directas o indirectas a favor de los insurgentes causando desorden, será inmediatamente muerto por la tro-

22 Dichos juicios y declaraciones pueden encontrarse en el Fondo Emancipación del Archivo General de Sucre, Bolivia (ABNB) años 1810-1814. 
pa, sin distinción de sexo (....) Que todos guarden silencio (...) no causar ruido, alternativas disputas, y otras cuestiones que disipan el tiempo (...) se prohíbe toda conversación o discurso que conspire a interpretar estas prevenciones que deben (...) cumplir literalmente. (Juan Ramírez, La Plata, noviembre de 1811. En ABNB. Fondo Emancipación 67)

\section{La guerra vista desde Charcas: Joaquín de la Pezuela y José de la Serna (1813-1825)}

\section{Experiencias de Joaquín de la Pezuela en suelo altoperua- no}

Joaquín de la Pezuela nació en Naval, provincia de Aragón, España, en 1761. De amplios conocimientos militares, participó activamente en los cuerpos castrenses españoles y fue nombrado coronel en 1803. En 1805, fue enviado al Perú para encargarse de la subinspección de artillería en Lima, a fin de reforzar la propuesta militar de los Borbones en América.

A través del estudio de sus memorias, cartas, notificaciones, proclamas y bandos es posible vislumbrar sus percepciones sobre la difusión de la revolución iniciada en Buenos Aires, la adhesión a la causa realista en el Alto Perú por parte de la población nativa y las expectativas de éxito en este suelo y en las provincias del actual territorio argentino.

Sus memorias fueron escritas luego del relevo de su cargo como jefe del Ejército Real en el Alto Perú y de haber asumido la dirección del virreinato, es decir, relata sus expediciones y experiencias de guerra en este espacio desde 1813 hasta 1816. En ellas, puede reconocerse un rico relato sobre la guerra, las necesidades de reclutamiento y recursos cons- 
tantes, la reorganización que él realizó en el ejército y los cuerpos militares que se incorporaron venidos de Espańa y otras regiones del Perú para enfrentar al ejército revolucionario que avanzaba con hombres, armas y recursos provistos por la población aledaña, pero también con las armas de "la seducción” y la opinión a su favor. También relata la guerra de guerrillas que debió afrontar por parte de los principales líderes guerrilleros, que respondían directamente al ejército revolucionario dirigido desde Buenos Aires.

Desde su asunción al mando en julio de 1813, comenzó a observar el grado de deserción de las filas de los diferentes regimientos. ${ }^{23}$ Hacía notar así, la "mala gana” de las tropas que habían ido a Huaqui y que luego de las derrotas sufridas, tanto los "juramentados de Salta" como los paisanos, inducían a los soldados a la deserción (Sobrevilla, 2011, pp. XI-XIII).

Al encontrarse en 1813 con los cuerpos militares de Goyeneche acantonados en Oruro, logró calcular un ejército de 3044 hombres, a los que sumó el de artillería que había traído a Lima. También relata cómo las tropas integradas por indígenas iban siempre acompañadas por sus mujeres, "siempre al lado sin podérselas quitar, so pena de desertarse infaliblemente". Estas mujeres hacían su comida y hasta robaban alimentos en los pueblos por donde transitaba el ejército (Pe306 zuela, 2011, pp. 8-9).

23 En un informe posterior fechado en 1818, siendo virrey, Pezuela continuaba advirtiendo la falta de motivación para participar en esta guerra y que (...) "todas las provincias del virreinato, aunque no sean afectan al Rey, aborrecen la larga inquietud de la guerra que padecen” Informe de Pezuela, 13 de noviembre de 1818, Archivo General de Indias (AGI) Sevilla, Estado, 74, citado en De la Puente Cándamo, 2015, p. 174). 
Según los relatos de Pezuela, la mayoría de los integrantes del ejército heredado de Goyeneche eran "indios" del sur de Perú - principalmente de las provincias de Arequipa, Puno y Cusco- que habían logrado establecer acuerdos para participar en las tropas fidelistas. No obstante, Pezuela señalaba que "los indios del Alto Perú aborrecían al soldado", los "mataban a palos", ya que "odiaban todo lo que era del Rey", es decir, seguían a las tropas revolucionarias no por voluntad propia, sino como retribución, debido a que los "porteños los halagaban con la igualdad y libertad de tributos". Para él, los indios no tenían preferencia por uno u otro bando (Pezuela, 2011, p. 9).

¿Cómo veía Pezuela la guerra en el territorio de Charcas? Al igual que Goyeneche, que había transitado los mismos caminos y experimentado similares percepciones sobre la adhesión a la causa del rey, observaba una resistencia casi generalizada ante las convocatorias, pero una amplia adhesión hacia los revolucionarios: "las tres cuartas partes de sus habitantes eran decididos por el sistema de ellos y los ayudaban con extraordinaria voluntad, especialmente los curas y frailes, que son los que más daño han causado a las armas del Rey, moviendo a sus feligreses en los púlpitos y hasta en los confesionarios a que siguiesen el partido de la independencia”. ${ }^{24}$

24 José Canterac, otro jefe realista, brigadier del Estado Mayor a cargo del ejército del Alto Perú, señalaba también en 1818 las características de esta población, que en su mayoría continuaba adhiriéndose a los revolucionarios, aunque esta lucha por la "patria" -llamada así por los insurgentes- "no es por amor que lo tengan y sí por haber sido seducidos y alucinados por algún cabecilla de opinión" (Colección Documental de la Independencia del Perú, V, t. 1, 1971, p. 21). 
Al referirse a la batalla de Vilcapugio, relata la exhortación que había enunciado ante todo el ejército previo al enfrentamiento y cómo había intentado convencer a sus interlocutores que una derrota de esa envergadura significaba la pérdida de todo el territorio de América meridional, con Lima incluida, al estar íntimamente conectados los revolucionarios de Buenos Aires "con los del norte que estaba por la parte de Santa Fe, Quito y Caracas en una general revolución con no pocos progresos y con iguales ideas que los del Río de la Plata de conseguir su independencia" (Pezuela, 2011, p. 12). Es notorio a lo largo de sus relatos su amplio conocimiento de las noticias de todo el espacio americano, sobre todo en materia de los avances de las tropas consideradas "enemigas".

Como una forma de lograr mayor adhesión a la causa del rey, Pezuela decidió nombrar generala del ejército a la Virgen del Carmen "para que le continuase con la protección que hasta allí se había dignado concederle" (Pezuela, 2011, p. 31). Ese mismo recurso fue utilizado por el líder revolucionario Manuel Belgrano para atraer a las tropas e identificarlas con la causa de la "patria", más allá de sus propias convicciones religiosas (Ortemberg, 2012).

Pezuela narra que en 1814, con una fuerza de 4.000 hombres, incluidos 450 de caballería y 200 artilleros, su objetivo era 308 continuar la marcha sobre el Tucumán, el cual, luego de la batalla librada en dicho espacio, se había constituido en el límite septentrional de la revolución. No obstante, los posteriores problemas surgidos en el Alto Perú y la capacidad de las provincias altoperuanas de "entretenerlo" para no avanzar hacia el sur, "y poner en práctica sus intenciones de revolucionarse", tornaron imposible continuar hacia dicho destino (Pezuela, 2011, p. 37). Las continuas deserciones lo mantenían incomu- 
nicado de lo ocurrido en la capital tucumana, donde se hallaba acantonado el ejército enemigo desde fines de 1815 "con su cuartel general a la orden de su nuevo caudillo José Rondeau, que sucedió en el mando a Belgrano" (Pezuela, 2011, p. 38). A ello se sumaban las noticias recibidas sobre la situación en Montevideo y la revolución que había estallado en Cusco en 1814, que habían vuelto inadmisible continuar más allá de las provincias invadidas de Salta y Jujuy. ${ }^{25}$

Pese a estos avatares, Pezuela no había perdido las esperanzas de triunfar, apoyándose en la vuelta al trono de Fernando VII, el triunfo de Rancagua, en Chile, y la venida de un numeroso contingente de oficiales espańoles para continuar la guerra con los revolucionarios y sofocar el sistema de guerrillas que estaban dejando sin recursos ni hombres al ejército real en el suelo altoperuano y en las actuales provincias de Salta y Jujuy.

Ya el mismo rey Fernando, al retornar de su cautiverio, con el fin de aquietar las aguas y consensuar intereses, había prometido en una proclama dirigida a los "españoles" respetar los cambios establecidos por la Constitución liberal de Cádiz de 1812:

25 Las memorias de Juan José Alcón relatan las hazañas que debió enfrentar el general Ramírez, quien a las órdenes del general Pezuela logró sofocar la revolución estallada en Cusco en 1814, llevada a cabo por oficiales y tropas realistas que se habían rebelado. Cfr. "Diario de la expedición del mariscal de campo, Don Juan Ramírez sobre las provincias interiores de La Paz, Puno, Arequipa y Cuzco”. Por Don Juan José Alcón, teniente agregado de la misma expedición. (Colección Documental de la Independencia del Perú, XXVI, t. I, pp. 391-425). Asimismo, las memorias del general Andrés García Camba (1916) describen los sucesos ocurridos durante la guerra en este espacio, desde la perspectiva de este oficial realista. 
(...) "Los tres saludos que me han hecho -las tropas y los generales- de Viva el Rey, viva la Nación, viva la Constitución, serán para siempre un testimonio indeleble de la obediencia a sus jefes, y a la soberanía. Españoles, Fernando VII, vuestro soberano os habla desde los límites de Cataluña, y os llama a que vengáis a mi trono, y el desvalido, y el pobre, y el perseguido (...) venid a mi trono de pacificación y de amor. (Citado en Odriozola 1863, IV, pp. 117-119).

No obstante estas promesas, la inmediata disposición del rey una vez retornado al trono, fue la de revocar la Constitución gaditana y volver a la política absolutista, desconociendo los cambios ocurridos a nivel legislativo y gubernativo. ${ }^{26}$

La guerra entre ambos bandos se desarrolló con mayor intensidad en el Charcas y en las provincias de Salta y Jujuy, que en varias ocasiones fueron ocupadas por las tropas del rey y debieron afrontar el conflicto de forma más próxima. ${ }^{27} \mathrm{~A}$ partir de 1816, el ejército auxiliar se acantonó en Tucumán como retaguardia y Belgrano se encargó de disciplinar a los cuerpos e instruir militarmente a las tropas. El conflicto más grave se desarrolló en los otros espacios anteriormente mencionados, donde la guerra se tornó más cruenta por la resistencia de buena parte de las autoridades y de los grupos étnicos, que

26 En otra proclama, dirigida a los "españoles americanos" y escrita luego de la revolución de Riego en 1820, reconocía sus errores cometidos al volver de su cautiverio y daba nuevamente esperanzas a todos los ciudadanos de la "Nación española" de respetar las autonomías y derechos establecidos en la legislación gaditana. Proclama del Rey a los habitantes de ultramar, los “españoles americanos" (citado en Odriozola, 1863, IV, pp. 86-88.

27 La experiencia de las invasiones realistas en las provincias de Salta y Jujuy, junto con la guerra de guerrillas liderada por Martín Miguel de Güemes y sus "gauchos infernales" fueron analizadas por Sara Mata (Mata 1999, 2002, 2007, 2009). 
entraron en una pugna de intereses e identificación con una y otra causa basada en sus propios requerimientos y pactos constituidos desde tiempos coloniales. A ello se sumaron las guerrillas que pronto se implementaron y pusieron en jaque constante al ejército del rey $^{28}$ mediante ataques esporádicos tendientes a debilitar y devastar al enemigo, dejándolo sin hombres, provisiones ni recursos con que abastecerse e impidiendo que las tropas realistas, principalmente durante los ańos 1814 a 1816, pudieran avanzar y tomar el control del territorio de las Provincias Unidas del Río de la Plata. ${ }^{29}$

Esta lucha contra las guerrillas y los papeles seductivos difundidos por el bando contrario constituían una de las mayores preocupaciones de Pezuela en esta "guerra de opinión" y seducción, a cargo del ejército enemigo (Pezuela, 2011, p. 43).

28 Una vez sofocadas las sublevaciones indígenas a principios de 1812, surgieron diferentes "caudillos" que mantuvieron un ambiente de insurgencia en la región, a la espera de la llegada del nuevo ejército revolucionario. La actuación de estos líderes, entre 1811 y 1813, permite relacionar este tipo de sublevaciones indígenas previas con la organización de un sistema de guerrillas que constituyeron a partir de 1814 y hasta fines de 1816 la base de la resistencia insurgente en el Alto Perú frente al ejército virreinal (Soux, 2015, pp. 212-220).

29 En contraposición con lo sostenido por la historiografía tradicional sobre el sistema de guerrillas -al cual prefirió catalogarlas "republiquetas"- los estudios de los últimos años apuntan a considerar esta estrategia de guerra como un sistema sumamente organizado y jerárquico, con un líder a la cabeza, pero subordinado a un gobierno superior -en este caso, el revolucionario de Buenos Aires- a quien prestaron apoyo constante y abrieron el camino a un territorio de difícil acceso. Sin embargo, luego de la derrota del ejército de Rondeau en noviembre de 1815 y la posterior muerte de sus principales líderes entre 1816 y 1817, las guerrillas entraron en decadencia y quedó un único bastión de la insurgencia en el valle de Cochabamba y La Paz (Soux, 2015). 
En una proclama de 1815 dirigida a sus batallones, Pezuela instaba a continuar la lucha contra el enemigo, pues a pesar de los avances de las tropas y la difusión de los ideales revolucionarios, Rondeau y los demás jefes seguidores llegarían a "estremecerse" al llegar nuevos refuerzos que se esperaban de España, que junto a "a los leales españoles de aquí y de allí, entreverados, entusiasmados y armados" actuarían en "indisoluble confraternidad por la Sagrada Causa del Rey y para destrucción de los enemigos de ella" (Pezuela Cuartel General de Challapata, 15 de julio de 1815, ABNB, Fondo Joaquín de la Pezuela, Cuaderno 2).

Siendo ya virrey, en dos informes dirigidos al ministro de Estado, Pezuela anoticiaba sobre las derrotas sufridas en Maipú, los avances continuos de los revolucionarios y sus intenciones de llevar a cabo sus antiguos planes de invadir por mar sus dominios y la necesidad urgente del envío de refuerzos para hacer frente a esta posible invasión. No obstante, consideraba que las provincias del bajo y Alto Perú en general permanecían aún tranquilas, estando el ejército de Belgrano estacionado en Tucumán, aunque amenazaba con una proliferación de proclamas difundidas por su imprenta "corrompiendo la opinión", "con el arte de engańar y seducir" y con partidas de gauchos lideradas por el caudillo Güemes. Pese a toda esta situación, "el aspecto y semblante político del vi-

312 rreinato y provincias del Alto Perú, no está por Buenos Aires" (Pezuela, Lima, julio de 1818, Colección Documental de la Independencia del Perú, XXII, II, pp. 23-27, 40-44).

En el contexto de 1818, la guerra había tomado otro color y las sospechas de invasión por mar de las tropas del general San Martín ya se habían difundido. A ello se sumaban los temores de propagación cada vez más acelerada de los ideales 
revolucionarios y de las incursiones de las partidas de gauchos y guerrilleros que continuaban bloqueando el paso de las tropas reales en suelo altoperuano, pese a haber sofocado a los principales cabecillas. No obstante, su percepción de la situación continuaba siendo alentadora, probablemente porque esperaba nuevos refuerzos de la metrópoli. ${ }^{30}$

Durante el período de reinstalación del absolutismo, Pezuela, al ser designado virrey en 1816, fue el responsable de volver al statu quo de 1808 y lograr una "pacificación realista" en los territorios de la Audiencia de Charcas y la Capitanía General de Chile, esta última sin poder llevarse a cabo, debido a los triunfos de las fuerzas patriotas en Chacabuco y Maipú en 1817 y 1818. A partir de 1820, con la reinstauración de la Constitución de 1820, Pezuela solo llegó a restablecer la diputación provincial de Lima y otros ayuntamientos constitucionales en los territorios que se hallaban bajo su control. Otras medidas no pudieron implementarse, a causa del motín militar que culminó con su deposición en enero de 1821 (Peralta Ruiz, 2005, pp. 485-501).

Otros jefes realistas que actuaron en el territorio altoperuano también dejaron plasmadas sus experiencias de guerra y sus medidas llevadas a cabo con los enemigos en las provincias altoperuanas recuperadas tendientes a unificar la opinión acorde con sus ideales, revocar medidas o disposiciones efec-

30 En los informes dirigidos a Espańa, esta falta de reconocimiento de la situación que podría significar más bien un ocultamiento de los verdaderos avances de las tropas revolucionarias fue un recurso también utilizado por las anteriores autoridades, como Abascal y Goyeneche. 
tuadas por autoridades del bando contrario ${ }^{31} \mathrm{y}$, al mismo tiempo, otorgar una serie de concesiones a los miembros de su ejército para evitar la deserción alarmante. ${ }^{32}$

Con respecto al problema de las continuas deserciones, común en ambos bandos enfrentados, ${ }^{33}$ Susana Llontop ha señalado que estas fueron detalladas ampliamente por las diferentes autoridades y oficiales del bando realista, quienes relataban que muchos miembros de sus tropas se adherían al bando revolucionario, no por convencimiento a la causa, sino "por la esperanza y codicia del saqueo". Según palabras del general Ramírez, lo hacían en épocas de labores en las cosechas o por sublevaciones o movimientos revolucionarios a los que se adherían, de acuerdo con sus intereses (Llontop, 1969, pp. 71, 317-372).

\section{José de la Serna a cargo del Ejército Real (1816-1821) y del virreinato del Perú (1821-1825)}

Al ser elegido virrey en 1816, Pezuela tuvo las primeras diferencias y roces con el nuevo general en jefe a cargo del ejér-

31 Tales como la medida tomada por el general Gerónimo de Lombera, respondiendo órdenes del general Ramírez, de recoger de la población la moneda revolucionaria del sol y realizar la reposición de igual valor con "moneda legítima". ABNB. Fondo Emancipación. Número 168.

32 Este tipo de consideraciones se encuentran registradas en la documentación inédita existente en la Biblioteca Nacional de Lima, Perú.

33 La deserción constituyó un problema recurrente en ambos bandos, por lo que las autoridades y jefes de los cuerpos militares tuvieron la constante necesidad de establecer todo tipo de concesiones -pago efectivo de los sueldos, licencias, premios, condecoraciones- para propiciar mayor identificación con la causa que debían defender (Davio, 2011, pp. 29-49). 
cito del Alto Perú, el recién llegado de España, José de la Serna. $\mathrm{Al}$ respecto, la historiografía más reciente ha señalado que más que discordancias ideológicas entre uno y otro, ${ }^{34}$ los problemas habrían surgido por las estrategias diferentes de guerra, las ambiciones de poder, las enemistades y otros factores de carácter personal, que habrían pesado decisivamente en las relaciones entre diferentes jefes realistas y no solo entre los dos mencionados (De la Puente Brunke, 2012, pp. 190191; Mazzeo de Vivó, 2009, pp. 109-110).

De la Serna, que venía con amplios conocimientos militares y experiencia contra las fuerzas napoleónicas en la Península, llegó a Charcas en 1816. Fue nombrado por el rey Fernando VII para tomar el cargo de general en jefe del ejército en la lucha contra los revolucionarios. Su estrategia de guerra era diferente de la que desarrollaba Pezuela, más acorde este con una guerra ofensiva, sin dar importancia a la amenaza chilena o la posibilidad de un ataque de los revolucionarios por vía marítima. ${ }^{35}$

Según señala Albi (2009, pp. 156-157), hasta la llegada de la Serna, la guerra contra los revolucionarios se conducía con cierta improvisación. Una vez arribado este, se modernizaron la infraestructura militar, las técnicas y la disciplina con el objeto de lograr un trabajo conjunto entre las tropas, en su mayoría americanas, y los recién llegados europeos. Ade-

34 La historiografía más tradicional ya había señalado que las diferencias se centraban en cuestiones político-ideológicas, Pezuela era de tendencia absolutista y De la Serna, liberal.

35 De la Serna y otros jefes realistas, como Canterac y Valdés, discrepaban con la insistente opinión de Pezuela de atacar a los rioplatenses desde el territorio altoperuano y estaban convencidos de que el dominio de Lima no significaba el total control del Perú (De la Puente Brunke, 2012, 192). 
más, entre las novedades que introdujo hubo cierta "humanización” del conflicto, pues estableció consideraciones a los reclutas, licencias o premios para evitar la deserción masiva. Este tipo de concesiones y consideraciones ya se aplicaban también en el bando revolucionario (Davio, 2010).

De la Serna no dejó memorias, por lo que se han explorado oficios, informes y proclamas para conocer sus experiencias en el campo de batalla y sus percepciones sobre sus opciones políticas, además de la bibliografía sobre la cuestión.

El clima que vivió el Perú entre 1818 y 1821, es decir, entre la derrota de Maipú en Chile y la llegada de San Martín al Perú por las costas del Pacífico, fue sumamente crítico para la población peruana por la proliferaron de temores, rumores, sugestiones, la persuasión, la distorsión de la realidad, la deserción y la desilusión ante un futuro incierto (Mazzeo de Vivó, 2005, p. 170). Ya desde los inicios del proceso revolucionario en América del Sur, las noticias sobre el acontecer político y militar eran conocidas por todos los sectores sociales en diferentes ámbitos de sociabilidad. Los comentarios difundidos en lugares públicos, como las calles o pulperías, los bandos militares y proclamas anunciados por los jefes, y las noticias difundidas por los curas en las parroquias rurales constituyeron canales de información por los cuales se acce-

316 día al conocimiento de los sucesos políticos y militares y se asumía una posición al respecto. A esto se sumó la proliferación de rumores en diferentes espacios, que permitieron la difusión de noticias políticas y militares sin el riesgo de ser descubiertas (Davio, 2011a, 2017).

Las diferencias internas entre Pezuela y De la Serna, finalmente, desembocaron en el motín de Aznapuquio en enero 
de 1821, una suerte de golpe de Estado ocasionado por los militares que respondían a De la Serna y provocaron el derrocamiento del primero y la asunción del segundo como nuevo virrey.

Con la llegada de José de San Martín en 1821 a las costas peruanas y al puerto del Callao y la adhesión cada vez mayor a las tropas e ideales revolucionarios, De la Serna decidió trasladar la capital al Cusco para continuar la resistencia realista desde allí, la cual duró hasta 1824 .

A diferencia de lo expresado por la historiografía más tradicional, los últimos análisis han señalado que De la Serna llegó a aplicar los principios de la Constitución de Cádiz en las provincias del sur peruano durante el "trienio liberal". ${ }^{36} \mathrm{De}$ esta manera, se fue gestando un enfrentamiento entre nacionales y patriotas, que con el retorno al absolutismo en 1824 posicionaría aún más la balanza a favor de estos últimos y su proyecto independentista (Sala I Vila, 2011, pp. 693-694).

En Charcas, dicha constitución no llegó a implementarse totalmente, ya que había un verdadero vacío de poder y solo funcionaban los cabildos (Soux, 2015, p. 227). Sin embargo, durante ese período los territorios del sur peruano y Charcas lograron cierta autonomía frente a las pretensiones del centralismo limeño (Sala I Vila, 2011, p. 695; 2016, p. 53).

En un informe dirigido a Espańa, De la Serna explicitaba su resolución de defender la causa del rey desde el Cusco, la situación y posición de las tropas de su ejército y su "visión

36 Los principios también fueron establecidos con la revolución de Riego en España en 1820. 
triunfalista” (Mazzeo de Vivó, 2009), pese a los avances de los "patriotas": "La vanguardia, a las órdenes de Olañeta, ocupa la antigua línea de Tarija, Tupiza y la Rinconada, haciendo sus incursiones sobre Huamahuaca y el miserable estado que se hallan los enemigos por los puntos de su frente, envueltos en una horrorosa anarquía, alejan por ahora todo recelo de que sea atacada ni molestada en sus posiciones" (De la Serna, Lima, 20 de marzo de 1821, Colección Documental de la Independencia del Perú, XXII, t. II, pp. 71-73). Sin embargo, enfatizaba a la Corona espańola la extrema urgencia del envío de recursos para la continuación de la guerra.

A pesar de su exhortación a la población, que enarbolaba la bandera de los principios liberales y constitucionales, pronto debió enfrentar diferencias internas con Manuel Antonio de Olañeta, uno de sus jefes subordinados encargado de la guerra en el territorio altoperuano. A ello se sumaron las opiniones de revolucionarios, como San Martín, que intentaban con sus discursos desenmascarar "su intención tirana" bajo un aparente signo de liberalidad (Proclama de San Martin a los habitantes del Perú, Colección Documental de la Independencia del Perú, VI, t. 4, pp. 107-108).

Las discordancias entre De la Serna y Olañeta llevaron en enero de 1824 a la rebelión de este último en el mismo seno del ejército, pretendiendo imponerse como representante del absolutismo en el territorio de Charcas, en lo que se conoce como "guerra doméstica" (Soux, 2015, pp. 227). Dicha situación contribuiría a un debilitamiento aún más pronunciado del poder realista en este espacio. ${ }^{37}$

37 Hasta Simón Bolívar, atento a estas divergencias con De la Serna, intentó cooptarlo ofreciéndole cargos para que apoyara al ejército patriota. 
En una de sus proclamas difundidas, Olañeta pretendió convencer a los pueblos del "Alto y Bajo Perú" a adherirse y prestar apoyo a su mando, para contribuir a la verdadera defensa de "el Rey y los derechos de la nación española" (Manuel Antonio de Olañeta, Cuartel General de Potosí, 4 de febrero de 2824, Colección Documental de la Independencia del Perú, XXII, t. 3, p. 82).

Recientes estudios han considerado que el discurso absolutista de Olańeta fue adoptado por las élites autonomistas de Charcas frente a los intereses peruanos y rioplatenses vigentes desde 1809 (Irurozqui 2016, p. 159). Es decir, la retórica antiliberal habría respondido más a una estrategia a favor de las pretensiones autonomistas y de autogestión de las élites chaqueñas que a claros principios ideológicos (Irurozqui y Peralta Ruiz, 2014, p. 555). Las batallas de Junín y Ayacucho no solo acabarían con el poder realista representado por la figura de la Serna, sino también con el discurso absolutista de Olañeta y las pretensiones de las élites charqueñas (Irurozqui y Peralta Ruiz, 2014, p. 558).

Por su parte, De la Serna ya había redactado y difundido varias proclamas a los habitantes del Perú y bajo Perú, con el objeto de convencer de los engaños y la seducción de los "patriotas" liderados por San Martín (José de la Serna, Colección Documental de la Independencia del Perú, XXII, t. 3, pp. 176-179). En una de ellas, dirigida a los "indios del bajo Perú", exhortaba su colaboración como hermanos y a no dejarse seducir por los revolucionarios y les pedía que suministraran víveres y demás auxilio para sus tropas, a fin de conservar sus bienes y tierras (José de la Serna, Lurín, 8 de julio de 1821, Colección Documental de la Independencia del Perú, XXII, t. 3, p. 119). 
La batalla de Ayacucho, sucedida el 23 de diciembre de 1824, produjo el triunfo de las armas del ejército libertador al mando de Bolívar sobre las del virrey De la Serna. Asimismo, en 1825 Olañeta fue vencido definitivamente en la batalla de Tumusla, lo que dio fin a las operaciones realistas y abrió paso a la unánime decisión de declarar la independencia en 1826 (Soux, 2015, p. 235).

\section{Consideraciones finales}

Por medio del análisis de los discursos emitidos por representantes claves del bando realista, como Fernando de Abascal, Joaquín de la Pezuela, José de la Serna y de otros jefes y autoridades subalternas del mismo proyecto político, podemos considerar algunas reflexiones sobre los acontecimientos sucedidos a raíz de la propagación de los ideales revolucionarios en todo el territorio perteneciente al virreinato del Perú y de los territorios anexados, como es el caso específico de Charcas.

De acuerdo con los aportes de la historia conceptual, se observa que los significados de los conceptos utilizados por los representantes del bando realista remiten a sus propias percepciones sobre la guerra y la revolución, y se identifican con la insurgencia, la anarquía y el desorden, que debían erradicarse para continuar el óptimo funcionamiento del orden colonial instaurado desde hacía tres siglos. Como hemos visto, la idea de la "patria" se identificaba con la defensa de la causa realista. Sin embargo, en las fuentes -y de acuerdo con lo planteado por la historiografía- hay una progresiva resignificación de este término, así como el de los "patriotas" identificados con la causa revolucionaria, lo que conlleva a 
su asimilación, desde la perspectiva realista, con la noción de insurgencia e insubordinación.

Una vez instalada la guerra en Charcas y anexadas estas provincias al virreinato conducido por el virrey Abascal en 1810, la necesidad de convocatoria a la causa política que debían defender y la fidelidad a la Corona española se convirtieron en un objetivo crucial que era necesario alcanzar. Asimismo, desde el establecimiento de la Constitución gaditana, se observó un acercamiento a principios liberales que garantizarían su permanencia en el poder. Sin embargo, en el transcurso de la guerra, se tornó cada vez más difícil llevarlos a cabo, debido a las múltiples cuestiones que debieron afrontar.

En primer lugar, en las comunidades indígenas y la población altoperuana en general encontraron una importante resistencia al reclutamiento e identificación con la causa del rey. Según ellos, esta población se adhería cada vez más a la causa patriota y a ello contribuía también la falta de armas y recursos materiales, que hacían de la guerra una necesidad acuciante y extenuante. Esta situación favoreció que las percepciones y experiencias de estos actores en el campo de batalla auguraran bajas expectativas a corto plazo sobre el triunfo de la causa y el mantenimiento del orden colonial. ${ }^{38}$ No obstante, a largo plazo sus expectativas presagiaban la posibilidad de ganar la guerra, pues se apoyaban en la esperanza de la llegada de recursos y apoyo externo provenientes de España.

38 A pesar de que este panorama se logró apaciguar a partir del retorno de Fernando VII en 1814, estos factores presentes en la primera etapa de la guerra volvieron a emerger debido a la falta de apoyo y recursos de España y a los continuos desacuerdos entre posteriores dirigentes de la causa acerca de la política que debían llevar a cabo con los insurgentes. 
En este aspecto, estaban convencidos de su triunfo, a pesar del reconocimiento de los aspectos negativos mencionados.

De acuerdo con ello, proporcionan claridad las experiencias de los jefes, oficiales y tropas de ambos bandos, que percibieron la guerra en el mismo espacio en disputa y dejaron plasmadas sus percepciones en múltiples documentos. En ellos, la desolación, el destierro, la devastación del territorio, las múltiples alianzas y pactos establecidos entre diversos grupos étnicos de acuerdo con los intereses puestos en juego y la identificación con la causa realista o revolucionaria se constituyeron en moneda corriente durante aquellos años claves del desarrollo de la guerra.

Las variadas y complejas visiones sobre los hechos que tuvieron los diferentes representantes a cargo de la dirigencia política y militar realista condujeron a la falta de efectividad de su propia causa, pese a las similitudes en las formas de convocatoria utilizadas por los propios revolucionarios. Estas experiencias y expectativas de los actores analizados fueron modificándose y complejizándose de acuerdo con los giros que fue tomando el conflicto, debido a la falta de identificación con esta causa de gran parte de la población altoperuana y de las tropas reclutadas en dicho suelo.

Los actores analizados pertenecientes al bando realista se hallaban sumamente preocupados por la "guerra de opinión" llevada a cabo por los revolucionarios, basada en la demonización del adversario y en el "arte de la seducción y el engaño", que ocasionaba bajas cada vez más pronunciadas de las filas del ejército. ${ }^{39}$

39 Como se ha sostenido, este tipo de guerra era concebida así desde ambos bandos y frecuentemente fue considerada mucho más grave y devastadora que la guerra de armas. 
A estos problemas se sumaron los múltiples desacuerdos y diferencias de opinión entre los dirigentes realistas. Es decir, estas divergencias, manifestadas en las estrategias de guerra, reclutamiento y las formas de convocatoria implementadas para exhortar a la población y a las tropas para que participen de manera activa identificándose con la causa terminaron contribuyendo al debilitamiento de la causa en el territorio en cuestión. Con la llegada de San Martín al Perú en 1821, el panorama se complejizó aún más y se agudizaron los conflictos y desavenencias que llevaron a la derrota definitiva y al pronunciamiento unánime a favor de la independencia entre 1825 y 1826 en el suelo altoperuano.

De acuerdo con José de la Puente Candamo, durante los años 1810 a 1815, la guerra instalada en el Alto Perú se convertiría poco a poco en materia medular de la emancipación hispanoamericana y punto de enlace comercial y de comunicaciones entre Lima y Buenos Aires (De la Puente Candamo, 2015, p. 172).

Por esta razón, Charcas quedó sumida en una guerra que parecía inacabable y su población se vio obligada a pronunciarse a favor de uno u otro bando, aunque simultáneamente ideaban sus propios proyectos políticos (Roca, 2007). En el transcurso del largo conflicto, este territorio permaneció en decidido jaque por parte de los revolucionarios, cuya causa, pese a los problemas y deserciones que ellos también debieron afrontar, fue ganando progresiva aceptación mediante una política basada en concesiones y premios para asegurar su adhesión y el sostenimiento de su causa.

Recibido: 07 de junio de 2017

Aprobado: 08 de abril de 2018 


\section{Fuentes inéditas de archivos}

Archivo y Biblioteca Nacionales de Bolivia. Sucre, Bolivia, Fondo Emancipación, Colección Rück y Fondo Joaquín de la Pezuela

Archivo General de la Nación, Buenos Aires, Argentina. Sala X, Ejército Auxiliar del Perú y Virreinato del Perú

Archivo General de la Nación, Lima, Perú. Fondo Colonial

Biblioteca Nacional del Perú. Documentos inéditos. Lima, Perú

Archivo de Historia y Antropología. Pueblo Libre, Lima, Perú

Archivo Histórico Militar del Perú, Lima, Perú.

Recibido: 07 de junio de 2017

Aprobado: 08 de abril de 2018

\section{Bibliografía}

Albi, de la Cuesta, Julio

(2009) El último Virrey. Madrid, Olleros y Ramos Editores.

324 Abascal y Sousa, J. F. de.

(1944) Memoria de gobierno del virrey Abascal. 1806-1816 (t. II). Editado por Vicente Rodríguez Casado y Antonio Calderón Quijano. Sevilla: Edición Católica Española.

Aillón Soria, E.

(2010) El mulato Francisco Ríos: líder y plebe (25 de mayo 1809- noviembre de 1810). En H. Bonilla (Ed.), In- 
dios, negros y mestizos en la independencia. Colombia: Planeta.

Bragoni, B. y Mata, S. (Comps.)

(2009) Entre la Colonia y la República. Insurgencias, rebeliones y cultura politica en América del Sur. Rosario: Prohistoria.

Colección Documental Emilio Gutiérrez de Quintanilla

(1973) Guerras de independencia (t. II). Buenos Aires: Dirección de Estudios Históricos.

Comisión Nacional de Sesquicentenerio de la Independencia del Perú (1972-1974) Colección Documental de la Independencia del Perú (varios tomos). Lima.

Contreras, C.

El aprendizaje de la libertad. Lima, Instituto Riva Agüero, Fondo Editorial.

Contreras, C. y Glave, L. M. (Eds.)

(2015) La independencia del Perú. ¿Concedida, conseguida, concebida? Lima, Instituto de Estudios Peruanos.

Contreras, C. y O'Phelan, S. (Eds.)

(2013) Crisis imperial e independencia. Perú 1808- 1830 (t. 1). Madrid, Penguin Random House Grupo Editor.

Davio, M.

(2010) Sectores populares militarizados en la cultura politica tucumana. 1812-1854 (Tesis doctoral inédita) (pp. 37-41). Universidad Nacional de General Sarmiento, IDES, Buenos Aires.

Davio, $M$.

(2011) ¿Vagos, traidores o desmotivados? Deserciones militares de los sectores populares en Tucumán durante la primera mitad del siglo XIX. Dimensión Antropológica, 54: 29-49. 
Davio, $M$.

(2011a) Rumores, difamaciones y canales de comunicación de los sectores populares durante el proceso de militarización en Tucumán (1812-1854). Rosario: Prohistoria. Recuperado de http://www.scielo. org.ar/scielo.php?script=sci_arttext $\&$ pid $=$ S1851 95042011000100003\&lng=es\&nrm=iso

Davio, $M$. (2015)

Con la espada y la palabra. Revolucionarios y realistas durante la guerra en Charcas. 1809-1813. Tinkazos, 18 (38): 109-126.

Davio, $M$. (2016)

La gran máquina de América del Sud se va precipitando hacia su ruina: percepciones y experiencias de los realistas durante la primera etapa de la guerra en el Alto Perú (1809-1814). Revista Investigaciones y Ensayos (63): 143-170.

Davio, $M$.

(2017) Construir la revolución desde la opinión: proclamas, bandos y exhortaciones durante la guerra en el Alto Perú (1810-1814). Nuevo Mundo Mundos Nuevos. Recuperado de http://nuevomundo.revues. $\operatorname{org} / 71268$

De la Puente Brunke, J.

(2012) Todo fue atolondramiento, todo confusión. Los militares realistas en la guerra de independencia del Perú y sus desavenencias. En C. Mc Evoy, M. Novoa y E. Palti. (Coords.), En el nudo del imperio. Independencia y democracia en el Perú (pp. 187-206). Lima: Instituto de Estudios Peruanos.

De la Puente Candamo, J.

(2015) Entre la fidelidad y la ruptura. En C. Contreras y L. M. Glave (Eds.), La independencia del Perú. ¿Concedida, conseguida, concebida? Lima, Instituto de Estudios Peruanos. 
Démelas, M. D.

(2007) Nacimiento de la guerra de guerrilla. El diario de José Santos Vargas (1814-1825). Ambassade de France en Bolivie, Plural.

Díaz Venteo, F.

Campañas militares del virrey Abascal. Sevilla, Escuela de Estudios Hispanoamericanos.

Etcheverri, M.

Los derechos de indios y esclavos realistas y la transformación política en Popayán, Nueva Granada. 1808-1820. Revista de Indias, LXIX (246): 45-72.

Etcheverri, M.

(2013)

Abascal, Cádiz y el realismo popular en Popayán, en S. O'Phelan y G. Lomné, Abascal y la contra-independencia en América del Sur, Lima, Fondo Editorial, Pontificia Universidad Católica del Perú, 2013: 449467.

Fernández Sebastián, J.

(2007) Iberconceptos. Hacia una historia transnacional de los conceptos políticos en el mundo iberoamericano. Isegoría, Revista de Filosofía Moral y Política (37): 165-176.

Fernández Sebastián, J. (Ed.).

(2009) Diccionario politico y social del mundo iberoamericano. La era de las revoluciones. 1750-1850. Madrid: Fundación Carolina.

Fernández Sebastián, J. (Ed.).

(2014) Diccionario politico y social del mundo iberoamericano. Conceptos politicos fundamentales 1770-1880. Madrid: Universidad del País Vasco, Centro de Estudios Políticos y Constitucionales. 
Fernández Sebastián, J. y Fuentes, F. (Eds.)

(2003) Diccionario politico y social del siglo XIX español. Madrid: Alianza Editorial.

Fradkin, R.

(2008) ¿Y el pueblo dónde está? Contribuciones para una historia popular de la revolución de independencia en el Río de la Plata. Buenos Aires: Prometeo.

Fradkin, R.

(2010) La revolución: guerra y orden social. En Dos siglos después. Los caminos de la Revolución (pp. 37-41). Rosario: Prohistoria Ediciones.

Fraser, R.

(2006) La maldita guerra de España. Historia social de la guerra de independencia. 1808-1814. Barcelona: Crítica.

García Camba, A.

(1916) Memorias para la historia de las armas españolas en el Perú, 1809-1825. Editorial América. Biblioteca Ayacucho.

García de Flöel, M.

(2000) La oposición española a la revolución por la independencia del Rio de la Plata entre 1810 y 1820. Parámetros jurídicos y politicos para la suerte de los españoles europeos. Hamburg, Hamburg Ibero-Amerian Studien.

328 Goldman, N.

(2008) Lenguaje y revolución. Conceptos politicos clave en el Rio de la Plata. 1780-1850. Buenos Aires: Prometeo.

Goldman, N.

(2009) ¡El pueblo quiere saber de qué se trata! Historia oculta de la Revolución de Mayo (pp. 62-64). Buenos Aires: Sudamericana. 
Hamnett, B.

(2000) La politica contrarrevolucionaria del virrey Abascal (pp. 5-15). Lima: Instituto de Estudios Peruanos.

Herreros de Tejada, L.

(1923) El General José Manuel de Goyeneche. Primer Conde de Huaqui. Apuntes y datos para su historia. Barcelona.

Irurozqui, $\mathrm{M}$.

(2005) De cómo el vecino hizo al ciudadano en Charcas y de cómo el ciudadano conservó al vecino en Bolivia. 1809-1830. En J. Rodríguez (Coord.). Revolución, independencia y las nuevas naciones de América (pp. 451-484). Madrid: Mapfre Tavera.

Irurozqui, $\mathrm{M}$.

(2011) Soberanía y castigo en Charcas, la represión militar y judicial en las juntas de La Plata y La Paz. 18081810. Revista Complutense de Historia de América 37: 49-72.

Irurozqui, $\mathrm{M}$.

(2016) La telaraña de los doctores. Charcas en el Congreso de Tucumán de 1816. Dossier: la Independencia más allá del Río de la Plata. Prismas. Revista de Historia intelectual (20): 153-160.

Irurozqui, M. y Peralta Ruiz, V.

(2014) Locos adoradores de Fernando VII. Pedro Antonio de Olañeta y el liberalismo hispánico en Charcas (1821-1825). Anuario de Estudios Bolivianos, Archivisticos y bibliográficos (20): 552-582.

Kosselleck, R.

(1993) Futuro pasado. Por una semántica de los tiempos históricos. Buenos Aires, Paidós. 
Kosselleck, R.

(2001) Los estratos del tiempo. Estudios sobre la Historia. Barcelona, Paidós.

Llontop de Sánchez Carrión, S.

(1971) Las deserciones del ejército realista (1810-1821). Boletin del Instituto Riva Agüero (8): 317-362.

Luqui Lagleyze, J.

(1996) Historia y campañas del ejército realista (t. I). Buenos Aires, Instituto Nacional Sanmartiniano, Fundación Mater Dei.

Martínez Riaza, A. (Ed.)

(2014) La independencia inconcebible. España y la pérdida del Perú. 1820-1824. Lima, Instituto Riva Agüero, Fondo Editorial.

Mata de López, S. (Comp.)

(1999) Persistencias y cambios. Salta y el noroeste argentino. 1770-1840. Rosario: Prohistoria.

Mata de López, S.

(2002) La guerra de independencia en Salta y la emergencia de nuevas relaciones de poder. Andes, Salta (13): 113-144.

Mata de López, S.

(2007) Los gauchos de Güemes. Buenos Aires: Eudeba.

330 Mata, S.

(2009) Revolución, insurgencia y guerra de independencia en América del Sur. Anuario IEHS, 24: 195-200.

Mazzeo de Vivó, C. A.

(2000) Las vicisitudes de la guerra de independencia en el Perú, 1817-1824. Cuadernos de Investigación (I, pp. 5-51). Lima, PUCP. 
Mazzeo de Vivó, C. A.

(2005) El miedo a la revolución de independencia del Perú, 1818-1824. En C. Rosas Lauro, El miedo en el Perú. Siglos XVI al XX (pp. 167-184). Lima: PUCP, Fondo Editorial.

Mazzeo de Vivó, C. A.

(2009) Los nudos de la desunión: conflictos y divergencias en la dirigencia del ejército realista durante la emancipación del Perú. 1810-1824. Revista de Indias 247: 105-135.

Mc Evoy, C. y Stuven, A. M. (Eds.).

(2007) La República peregrina. Hombres de armas y letras de América del Sur, 1800-1884. Lima, IFEA, IEP.

Méndez, C.

(1991) Los campesinos, la independencia y la iniciación de la República. El caso de los iquichanos realistas: Ayacucho, 1815-1818 (pp. 165-188). En H. Urbano (Comp.) y M. Lauer (Ed.). Poder y violencia en los Andes. Cusco: Centro Bartolomé de Las Casas.

Méndez, C.

(2005)

The plebeian republic. The Huanta rebellion and the making of the Peruvian State, 1820-1850. Durham and London: Duke University Press.

Odriozola, M. de.

(1863) Documentos históricos del Perú en la época del coloniaje, después de la conquista y de la independencia hasta 331 el presente (t. III, pp. 117-119). Lima.

O'Phelan, S.

(2014) La independencia en los Andes. Una historia conectada. Lima: Fondo Editorial del Congreso del Perú. 
O’Phelan, S. y Lomné, G.

(2013) Abascal y la contra-independencia en América del Sur. Lima, Fondo Editorial de la PUCP.

Orrego Penagos, J. L.

(2009) La contrarrevolución del virrey Abascal: Lima, 18061816. Procesos. Revista Ecuatoriana de Historia: 93112.

Ortemberg, P.

(2011) Joaquín de la Pezuela y la Virgen del Carmen. La trama religiosa de la guerra. En J. de la Pezuela, Compendio de los sucesos ocurridos en el Ejército del Perú y sus provincias (1813-1816). Santiago de Chile: Centro de Estudios del Bicentenario.

Ortemberg, P.

(2011a) Edición y estudios introductorios de Pablo Ortemberg y Natalia Sobrevilla. En J. de la Pezuela, Compendio de los sucesos ocurridos en el Ejército del Perú y sus provincias (1813-1816). Santiago de Chile: Centro de Estudios del Bicentenario.

Ortemberg, P.

(2012) Vírgenes generalas. Acción guerrera y práctica religiosa en las campañas del Alto Perú y el Río de la Plata (1810-1818). Boletín del Instituto de Historia Argentina y Americana Dr. Emilio Ravignani (35/36): 11-42.

332 Ortemberg, P.

(2014) Rituales de poder en Lima. 1735-1828: de la monarquia a la república. Lima: Fondo Editorial de Pontificia Universidad Católica del Perú.

Peralta Ruiz, V.

(2001) El Cabildo de Lima y la política en el Perú. En S. O'Phelan, La independencia en el Perú. De los Borbo- 
nes a Bolivar (pp. 29-56). Lima, Pontificia Universidad Católica del Perú, Instituto Riva Agüero.

Peralta Ruiz, V.

(2005) De absolutistas a constitucionales. Política y cultura en el gobierno del virrey Pezuela. Perú 1816-1820. En J. Rodríguez (Coord.). Revolución, independencia y las nuevas naciones de América (pp. 485-510). Madrid, Mapfre Tavera.

Peralta Ruiz, V.

(2006) El virrey Abascal y el espacio de poder en el Perú (1806-1816). Revista de Indias, LXVI (236): 165194.

Pezuela, J. de la.

(2011) Compendio de los sucesos ocurridos en el Ejército del Perú y sus provincias (1813-1816). Edición y estudios introductorios de Pablo Ortemberg y Natalia Sobrevilla. Santiago de Chile: Centro de Estudios Bicentenario.

Revilla Orias, P.

(2009) La autonomía revolucionaria de la Real Audiencia de Charcas hacia 1809: cimientos de un Estado independiente. Sucre: Casa de la Libertad, Fundación Cultural Banco Central de Bolivia.

Roca, J. L.

(2007) Ni con Lima ni con Buenos Aires. La formación de un Estado nacional en Charcas. Lima: Perú Plural.

Sala I Vila, N.

(2011) El trienio liberal en el virreinato peruano. Los ayuntamientos constitucionales en Arequipa, Cusco y Huamanga. 1820-1824. Revista de Indias, LXXI (253): 693-728. 
Sala I Vila, N.

(2016) Derecho, poder y libertad: a propósito de las batallas por la autonomía jurisdiccional de las Audiencias de Cusco y Charcas (1820-1825). Revista de Indias, LXXVI (266): 51-82.

Semprún, J. y Bullón de Mendoza, A.

(1992) El ejército realista en la independencia americana. Madrid, Mapfre.

Siles Salinas, J.

(2009) Historia de la independencia de Bolivia. La Paz, Plural.

Sobrevilla, N.

(2010) Hermanos, compañeros y amigos de sus mismos contrarios. Las guerras de independencia en el surandino. 1805-1825. En Dossier. Las guerras frente a la crisis del orden colonial. Hispanoamérica. Buenos Aires: Programa Buenos Aires de Historia Política del Siglo XX. Recuperado de http://historiapolitica. $\mathrm{com} /$ datos/biblioteca/sobrevilla.pdf.

Sobrevilla, N.

(2011) Introducción crítica al Compendio de los sucesos ocurridos en el Ejército del Perú y sus provincias (1813-1816). En J. de la Pezuela, Compendio de los sucesos ocurridos en el Ejército del Perú y sus provincias (1813-1816). Santiago de Chile: Centro de Estudios del Bicentenario.

334 Soux, M. L.

(2007) Proyectos leales e insurgentes en el Alto Perú. 18051826. Anuario de Historia Regional y de las Fronteras, XII (1): 75-109.

Soux, M. L.

(2009) Insurgencia y alianza. Estrategias de la participación indígena en el proceso de independencia en Charcas. (1809-1812), Estudios históricos, 27: 53-73. 
Soux, M. L.

(2013) Legalidad, legitimidad, lealtad. Apuntes sobre la compleja posición política en Charcas (1808-1811). En V. Hebrard y G. Verdó (Eds.), Las independencias iberoamericanas. Un objeto de la historia. Madrid: Casa de Velásquez.

Soux, M. L. (Coord.).

(2015) Bolivia, su historia. (t. III: Reformas, rebeliones e independencia. 1700-1825). La Paz: Coordinadora de Historia.

Thibaud, C.

Repúblicas en armas, los ejércitos bolivarianos en la guerra de independencia en Colombia y Venezuela. Bogotá, IFEA, Planeta.

Thibaud, C.

(2007) Definiendo el sujeto de la soberanía. Repúblicas y guerra en la Nueva Granada y Venezuela. 18081820. En M. Chust y J. Marchenna (Eds.). Las armas de la nación. Independencia y ciudadania en Hispanoamérica (1750-1850). Veuvert, Iberoamericana.

Vargas Esquerra, J. I.

(2004) Cuando no había rey, Abascal lo era de América. Tiempos de América (11): 15-26.

Vargas Esquerra, J. I.

(2010) Goyeneche, un americano al servicio del rey en el Alto Perú. Naveg@mérica. Revista electrónica de la Asociación Española de Americanistas (4). Recuperado de https://www.academia.edu/2341752/Goyeneche_un_americano_al_servicio_del_rey_en_el_ Alto_Per\%C3\%BA_1808-1813

Vargas Esquerra, J. I.

(2010) Un hombre contra un continente. José Abascal, Rey de América. 1806-1816. León: Akrón Historia. 
Discursos de los (con)vencidos: Abascal, Pezuela y De la Serna frente a la guerra en Charcas (1809-1825)

Velázquez, D.

(2014) Patria. Perú. En J. Fernández Sebastián (Ed.). Diccionario politico y social del mundo iberoamericano. Conceptos politicos fundamentales 1770-1880 (pp. 166173). Madrid, Universidad del País Vasco, Centro de Estudios Políticos y Constitucionales.

Wasserman, F.

(2008) Revolución. En N. Goldman (Ed.). Lenguaje y revolución. Conceptos políticos clave en el Río de la Plata. 1780-1850 (pp. 161-162). Buenos Aires: Prometeo. 